\title{
RECOGNITION OF CAN AND CAN'T
}

\author{
Eunice V. Pike \\ Summer Institute of Linguistics \\ University of Michigan
}

Because can and can't occur frequently and in sentences of like structure ( $C$ can go. I can't go) the Latin American who doesn't "hear the $t$ " is at a disadvantage. He uses some less convenient method for determining whether the speaker's response was negative or positive.

The problem of hearing the stop is not one confined to the words can and can't; rather it is related to all voiceless stops which, in word final position, follow homorganic nasals. That is, limb and limp, pine and pint sang and sank have a similar difficulty, but because they do not occur as frequently as the other two words, their meaning can usually be picked up by context.

In stressed position the phonetic pronunciation of the words ending with the nasal remains more or less constant as $\left[k^{\prime} \times n\right],[1 I m],\left[p^{\prime} a I n\right],[s * n]$. The pronunciation of the other half of the word pair, however, varies considerably. For example, the word can't may be pronounced with a heavily aspirated and released $\left[t^{2}\right],\left[k^{\prime}\right.$ ent $]$. Or it may be pronounced with an unrealeased $[\mathrm{t}]$ and a simultaneous glottal stop, $\left[k^{i} \times n ?^{t}\right]$. This final [?] may be anticipated by heavy or light laryngealization ${ }^{2}$ of the preceding $[n],\left[k^{\prime} x x^{\prime} t\right]$. $T_{G}$. L. Trager in "The Phoneme ' $t$ ': a Study in Theory and Method," American Speech, Vol. 17 (1942), pp. 144-8, speaks of an unreleased [t] which occurs in final position before a pause, and of a glottal stop with apicalization which o curs after a strong-stressed syllable before syllabic $[n]$, as in mountain.

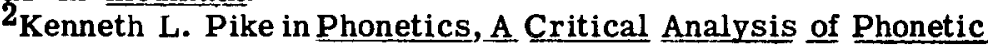
Theory and a Technic for the Practical Descriotion of Sounds, (Ann Arbor: University of Michigan Press, 1943) describes laryngealization as a trill of the vocal cords superimposed upon the vibration of the vocal cords. He notes that it may be "heard in the speech of people who are talking in a tone of voice very low as compared with normal style." Others have described laryngealization as "a voice which degenerates into a growl," or "singing two notes lower than he can." 


\section{Eunice V. Pike}

The vowel is frequently effected, not only by laryngealization but by nasalization as well. In fact, in sentence medial position the $[n]$ and $[t]$ may be lost entirely and only the nasali zation, laryngealization and glottal stop remain. [?aI $\mathrm{k}^{\prime}$ ? $\mathrm{gou}^{\mathrm{u}}$ ?.

Words ending in /mp, and /nk/ seldom use the extreme phonetic varieties which occur with those words ending with /nt/, but simultaneous closure of $[\mathrm{p}]$ with $[?]$ and $[\mathrm{k}]$ with [?] accompanied by laryngealization and nasalization is nevertheless frequent.

Because the [?] occurs in all three series of words, and because it is the factor that remains most constant within each series, I concentrated on the [?] and ignored, in my teaching procedures, the laryngealization and nasalization.

Because word final velar / $\mathrm{h} / \mathrm{vs}$. word final alveolar $/ \mathrm{n} /$ are a problem in themselves, I omitted them also from the drills.

Maria Mastrapa, a pharmacist from Cuba, was the student to whom I gave individual attention on this problem. In order to avoid the frustration that seemed to come to her at the sight of the words can and can't, we started with one of her own expressions ḿ? m, explained by her as mean ing, "I hear what you say, but I don't believe you." The glottal stop between the two nasals was pointed out and the expression was slowed down until it became very prominent.

Next we went to an English expression, "Thump them," reduced to [ $\theta$ am ?m]. After a few tries we dropped he "them" and said thump and contrasted it with thumb. Other words followed: clam and clamp, slum and slump, limb and limp. These words were put in sentences. In stressed position: He found a clam. He found a clamp. He saw the limb. He saw the limp. In unstressed position: The clam was on the ground. The clamp was on the ground. The limb was unusual. The limp was unusual.

Similarly word pairs ending with $/ \mathrm{n} /$ and $/ \mathrm{nt} /$ were drilled: tin and tint, pain and paint, sane and saint, ten and tent, men and meant, plan and plant, ran and rant, scan and scant, pun and punt, run and runt, shun and shunt, pine and pint, join and joint. It was observed that the quality of the 


\section{Recognition of Can and Can't}

vowel in the word pair did not seem to effect Miss Mastrapa's ability to hear the contrast.

The word pairs were put into contrastive sentences. He knows the plan. He knows the plant. The store sells window pane. The store sells window paint. He bought a new tin. He bought a new tint. The dogs pant. The dog's pan. He didn't like the run. He didn't like the runt. She bought the ten. She bought the tent.

Words in sentence medial position were considerably more difficult than those in sentence final position, and in order to make them somewhat easier they were first drilled with the sentence stress on the word under question. They pun frequently. They punt frequently. They ran every day. They rant levery day. The tin is expensive. The tint is expensive. He has a pine jar. He has a pint jar. He the plan down. He put the plant down.

Later the sentence stress was shifted to the last word in the sentence and Miss Mastrapa found it still harder to hear the contrast. They pun frequently. They punt/frequently. They ran everyday. They rant everyalay. He-menIgo. He meant $\mathrm{ge}$.

It was observed that when the word pair preceded a vowel the contrast was more easily heard then when it preceded a consonant. Perhaps the reason for this was that, preceding a vowel, the $\Lambda /$ frequently actualized as a flap, rather than the more usual glottal stop with simultaneous alveolar stop. Of those word pairs which were followed by consonants, the student had the most difficulty with those which preceded $/ \mathrm{t} /$ or $/ \mathrm{d} /$.

After watching the student's responses in the preced ing drills, I was able to grade the sentences with can and can't from easy to hard. Starting with the easy ones, the student built up confidence as she went along. He said I can. He said I can't. Suppose I can. Suppose I can't. I know I can. I know I can't. I can if she goes. I can't if she $\sqrt{g o e s}$. Can I gor? Can't I go? She can when she comes hece. She can't when she comes hare. She can mind the baby. 